\title{
HOPE AND SPIRITUAL WELL-BEING IN IRANIAN PATIENTS UNDERGOING CHEMOTHERAPY
}

\author{
Mohammad Fathi' ${ }^{1}$,Hero Hamzepour², John Gammon ${ }^{3}$, Daem Roshani ${ }^{4}$, Sina Valiee 5 \\ ${ }_{1}^{1}$ Assistant Professor, Department of Medical Surgical Nursing, Clinical Care Research Centre, Kurdistan University of Medical Sciences, \\ Sanandaj, Iran. \\ 2MSN, Student Research Committee, Kurdistan University of Medical Sciences, Sanandaj, Iran. \\ 3 Professor, Swansea University, College of Human and Health Sciences, Swansea, U. K. \\ ${ }^{4}$ Associate Professor, Social Determinants of Health Research Center, Research institute for Health Development, Kurdistan University \\ of Medical Sciences, Sanandaj, Iran. \\ ${ }_{5}^{5}$ Associate Professor, Department of Medical Surgical Nursing, Clinical Care Research Centre, Kurdistan University of Medical Sciences, \\ Sanandaj, Iran.
}

\section{ABSTRACT}

\section{BACKGROUND}

Cancer is a major well-being problem worldwide. Chemotherapy is one of the main therapeutic and systemic interventions of cancer. Hope is one of the most important factors in battling against cancer and its complication. During the experience of living with cancer, despite the fact that hope is threatened, the search for purpose and meaning of life continues and in this regard the role of spiritual well-being as an important aspect of leading a healthy life is significant.

Aim: This study is aimed to investigate hope and spiritual well-being in patients undergoing chemotherapy and it is a descriptive study.

\section{MATERIALS AND METHODS}

This study is descriptive and its population included all patients admitted to Tohid Hospital. Inclusion criteria included un dergoing chemotherapy, aged 18 and more, Muslim, awareness of disease and treatment, lack of mental illness, being hospitalised in the Oncology and Chemotherapy Tohid Medical Centre and willingness to participate in the study. According to the formula of sample size, it was estimated to be 97 patients. Convenience sampling methods was used and the data were collected in 6 months from October to March, 2015 - 2016.

\section{RESULTS}

In this study, 97 patients undergoing chemotherapy were evaluated. The average of hope was $2.84 \pm 0.38$ and the average of spiritual well-being was $4.22 \pm 0.61$, which was more than the average level in both cases. The average of religious well-being was $4.48 \pm 0.65$ and the average of existential well-being was $3.92 \pm 0.68$. Results showed 8 patients (3.8\%) had high spiritual wellbeing (100 - 120 scores) and 87 (90.6\%) patients had moderate spiritual well-being with (41 - 99 score). The findings also showed a negative correlation between hope and the original diagnosis time of disease $(p=-0.19, r=0.046)$. Also, there was a negative correlation between spiritual well-being and the original time of disease diagnosis $(p=-0.15, r=0.13)$. In other cases including age, place of residence, type of cancer and non-chemotherapy measure, there was not a significant relationship between hope and spiritual well-being among the groups $(\mathrm{p}>0 / 05)$.

\section{CONCLUSION}

There was a direct correlation between hope and spiritual well-being $(r=0.36, p=0.0001)$. Playing supportive and consulting role, oncology nurses should attempt to promote the dimension of care and hope, particularly in female patients with holistic care approach emphasising the spiritual aspect.

\section{KEY WORDS}

Cancer, Hope, Spiritual Well-being, Care, Iran.

HOW TO CITE THIS ARTICLE: Fathi M, Hamzepour H, Gammon J, et al. Hope and spiritual well-being in Iranian patients undergoing chemotherapy. J. Evolution Med. Dent. Sci. 2018;7(27):3106-3111, DOI: 10.14260/jemds/2018/698

'Financial or Other Competing Interest': The present study is the result of research project that has been approved by the research council of Kurdistan University of Medical Sciences, Sanandaj, Iran, No. IR.REC.MUK.1394.149. The authors declare that they have no conflicts of interest.

Submission 21-05-2018, Peer Review 16-06-2018,

Acceptance 22-06-2018, Published 02-07-2018.

Corresponding Author:

Sina Valiee,

BSN, MSN, PhD.

Associate Professor,

Clinical Care Research Centre,

Kurdistan University of Medical Sciences,

Sanandaj, Iran.

E-mail: valiee@muk.ar.ir

DOI: $10.14260 /$ jemds $/ 2018 / 698$

(c) $(1)$

\section{BACKGROUND}

Cancer is a major well-being problem worldwide. ${ }^{1}$ Cancer patients in 2020 was 15 million and it will reach 21 million in $2030 .^{2}$ In 2013, more than 165,0000 new cancer diagnoses were made in the United States. ${ }^{3}$ Cancer is the third leading cause of death in Iran. ${ }^{4}$

Chemotherapy is one of the main therapeutic and systemic interventions of cancer. ${ }^{3}$ More than $50 \%$ of cancer patients receive chemotherapy. So this method is effective to treat millions of patients suffering from cancer and return life to them. ${ }^{5}$ Using chemotherapy has side effects and impacts on the patient's well-being in emotional, social, physical and spiritual dimensions. ${ }^{6}$ 
As stated in the study, $59 \%$ of patients stated that chemotherapy is worse than the cancer itself.7 For example, chemotherapy can disrupt sleep patterns and activity, creating physical and psychological symptoms, disrupt social participation and denial of the ability to enjoy different aspects of patients' lives. ${ }^{8}$ Hope is one of the most important factors in battling against cancer and its complication. ${ }^{9}$ Hope is defined as a dynamic structure with the possibility of a better future than the current ambiguous problems and circumstances. $^{10}$ It is a fundamental resource in reconstructing human life. ${ }^{11}$ Hope, as a multi-dimensional concept, is a fundamental factor in elimination of despair in cancer patients. ${ }^{10}$ It involves imagination and attention of people to the future, considering the likelihood of achieving positive results from the treatment. It leads to more attempt from the patients. Hope is a multidimensional processoriented, dynamic, individualised and future-oriented concept. ${ }^{12}$ Cancer has more profound impact on hope than other diseases, ${ }^{10,11}$ and chemotherapy and its complications can lead to its reduction or elimination. ${ }^{13}$ Whereas patients basically choose chemotherapy hoping to recover.14 The nurses who take care of patients undergoing chemotherapy should pay close attention to identify and control the symptoms of their despair. ${ }^{15}$ During the experience of living with cancer, despite the fact that hope is threatened the search for purpose and meaning of life continues and in this regard the role of spiritual well-being as an important aspect of leading a healthy life is significant.16 The World Health Organisation claimed the spiritual well-being as the fourth pillar of health in 1979, but the dimensions of this very important element has not been known properly. ${ }^{17}$ Although, it is difficult to define mental well-being, ${ }^{18}$ as a predictor it provides important information about the need and ability to cope with stress and necessary interventions to adapt and cope with the crisis caused by severe diseases. ${ }^{19}$

Spiritual well-being is composed of two components: religious well-being and existential well-being. Religious well-being is a sign of connection with a higher power, i.e. God. Existential well-being is also a mental and social element and it is a sign of who he is, what and why he is doing and where he belongs to. Spiritual well-being dimension guides us toward God and the existential dimension leads us beyond ourselves and toward the environment and others. 20

When the spiritual well-being is seriously compromised, a person may suffer from mental disorders such as loneliness, depression and loss of meaning of life. Therefore, having support from religious or spiritual sources or having connection with a higher supreme power is beneficial and could be helpful in promoting quality of life, reduction and controlling the mental disorders, interpersonal support, reducing the severity of symptoms and as a result positive results of treatment.21 Spiritual well-being increases life expectancy and improves a person's social performance by creating energy and motivation in person. ${ }^{22}$ Hope and spiritual well-being are meaningful factors in life that help people to adapt with the circumstances of disease, reduce their mental tensions and promote their quality of life and mental and social well-being. ${ }^{13}$ Although, some of the conducted studies indicated that there is a correlation between hope and spiritual well-being. ${ }^{23}$ Cultural differences and the type and process of problem are effective in the results and level of this relationship. ${ }^{24}$ Therefore, the present study was conducted to analyse the hope and spiritual wellbeing in patients undergoing chemotherapy, determining the relationship between hope and spiritual well-being with demographic data of patients and analysing the correlation of hope with spiritual well-being in patients undergoing chemotherapy.

\section{MATERIALS AND METHODS}

This study is descriptive and its population included all patients admitted to Tohid Hospital. Inclusion criteria included undergoing chemotherapy, aged 18 and more, Muslim, awareness of disease and treatment, lack of mental illness, being hospitalised in the oncology and chemotherapy Tohid Medical Centre and willingness to participate in the study. According to similar previous studies that reported a correlation between spiritual well-being and hope in cancer patients, $\mathrm{R}=.27$ and with confidence $99 \%$. The minimum sample size in this study was 78 according to the formula-

$$
n=\frac{z_{1-\alpha / 2}^{2}\left(1-r^{2}\right)}{r^{2}}+2
$$

To ensure the results, we will select a minimum sample size of 97 people. Convenience sampling methods was used and the data were collected in 6 months from October to March 2015 - 2016.

Three questionnaires were used to collect data: demographic questionnaire which contained eight questions that determined gender, age, marital status, place of residence, education level, type of cancer, chemotherapy dose and non-chemotherapy treatment. Spiritual Well-Being Scale (SWBS) which was designed by Paloutzian and Ellison (1982) had two sections and 20 items. 10 items were related to religious well-being and 10 other items evaluated existential well-being. Odd numbers evaluated religious well-being and even numbers existential well-being. Answers to the questions were classified in the Likert scale of 6 options including: strongly disagree, disagree, somewhat disagree, somewhat agree, agree and strongly agree. Scores were graded in order from 1 to 6 and in negative questions grading was done reversely. The total of these two subgroups is the spiritual well-being score which ranged from $20-120$.

Spiritual well-being was classified in three levels: low (40-20), mediocre (99-41) and high (120-100).25 Validity and reliability of the questionnaire was measured by Cronbach's alpha in the studies as 99\%, 93\% respectively. ${ }^{17,24}$ Herth Hope Index which had 12 phrases and was graded according to 4 Likert scale scores. Point 1 for never applies, point 2 for does not apply, point 3 for applies and point 4 for it is considered. With regard to questions of 3 and 7 , scoring was reverse. ${ }^{26}$ The general scores for Herth Hope Index varies between 12 and 48. The higher scores indicated a better condition for hope. Reliability of the questionnaire had been approved in the previous foreign studies and its content had also been approved in several domestic studies. ${ }^{24}$ In order to facilitate understanding of the scores, they were classified according to the studies 13,24 in 4 levels: hopeful (40-48), mediocre hope (31-39), low hope (22-30) and hopeless.

This project was approved by Research Committee of Ethical Considerations at Kurdistan University of Medical Sciences and Ethics Committee at Kurdistan University of Medical Sciences with the code IR.REC.MUK.1394.149. Ethical 
considerations included authorisation of hospital officials, satisfaction and patient compliance, obtaining informed consent, ensuring the confidentiality of the results and allowing to leave the study if they want.

Research data was analysed using SPSS version 16 . In order to describe hope and spiritual well-being mean, standard deviation and frequency and percent of variables' tables were used and to assess the mean difference t-tests and one-way ANOVA were used. In order to determine the correlation coefficient of hope and spiritual well-being, Pearson correlation coefficient was used.

\section{RESULTS}

In this study, 97 patients undergoing chemotherapy were evaluated. 49 persons (5.50\%) were female and $80(82 \%)$ were married, location of life of 62 patients (64\%) was city and 56 patients $(7 / 57 \%)$ were illiterates. 73 patients $(75 \%)$ were less than 61 years and their age range was $18-77$. The most common types of cancer, 40 patients (41.2\%) were diagnosed with leukaemia. Since the early detection of cancer of 71 patients $(73 \%)$ less than a year had elapsed, 69 patients (71\%) had undergone chemotherapy at least 2 times and at most 6 times. 29 patients (30\%) had undergone surgery except for chemotherapy and 55 patients (56.7\%) had not done any remedial action other than chemotherapy (Table 1).

In this study, the average of hope was $2.84 \pm 0.38$ and the average of spiritual well-being was $4.22 \pm 0.61$, which was more than the average level in both cases. The average of religious well-being was $4.48 \pm 0.65$ and the average of existential well-being was $3.92 \pm 0.68$. Results showed 8 patients $(3.8 \%)$ had high spiritual well-being (100-120 scores) and $87(90.6 \%)$ patients had moderate spiritual wellbeing with (41-99 score) (Table 2).

The results of the T-independent test indicated that the average score of spiritual well-being is not equal among men and women ( $p=0.032)$. According to ANOVA, education level had not been influential on spiritual well-being. But the spiritual well-being and hope in people with less than diploma is more than other levels of education. The findings also showed a negative correlation between hope and the original diagnosis time of disease $(p=-0.19, r=0.046)$. Also, there was a negative correlation between spiritual well-being and the original time of disease diagnosis $(\mathrm{p}=-0.15, \mathrm{r}=0.13)$. In other cases including age, place of residence, type of cancer and non-chemotherapy measure, there was not a significant relationship between hope and spiritual well-being among the groups ( $p>0 / 05)$ (Table 3).

Using Pearson correlation test, a direct correlation between spiritual health and hope was found for patients undergoing chemotherapy referring to Tohid Medical Centre in Kurdistan province ( $\mathrm{r}=0.36, \mathrm{p}=0.0001$ ).

\begin{tabular}{|c|c|c|c|c|}
\hline Variables & $\begin{array}{c}\text { Spiritual } \\
\text { Well-being } \\
\text { Score }\end{array}$ & $\mathbf{P}$ & Hope Score & $\mathbf{P}$ \\
\hline \multicolumn{5}{|l|}{ Sex } \\
\hline Female & $4.088 \pm 0.646$ & \multirow[b]{2}{*}{0.032} & $2.817 \pm 0.381$ & \multirow[b]{2}{*}{0.550} \\
\hline Male & $4.358 \pm 0.552$ & & $2.865 \pm 0.399$ & \\
\hline \multicolumn{5}{|l|}{ Age } \\
\hline$<40$ & $4.198 \pm 0.658$ & \multirow{3}{*}{0.789} & $0.783 \pm 0.335$ & \multirow{3}{*}{0.289} \\
\hline $40-60$ & $4.190 \pm 0.67$ & & $2.822 \pm 0.423$ & \\
\hline$>60$ & $4.294 \pm 0.469$ & & $2.656 \pm 0.416$ & \\
\hline Marriage & & & & \\
\hline
\end{tabular}

\begin{tabular}{|c|c|c|c|c|}
\hline Single & $4.362 \pm 0.630$ & & $2.691 \pm 0.383$ & \\
\hline Married & $4.192 \pm 0.611$ & 0.315 & $2.873 \pm 0.385$ & 0.079 \\
\hline \multicolumn{5}{|l|}{ Residency } \\
\hline Village & $4.254 \pm 0.674$ & \multirow[b]{2}{*}{0.68} & $2.759 \pm 0.452$ & \multirow[b]{2}{*}{0.129} \\
\hline City & $4.201 \pm 0.581$ & & $2.886 \pm 0.344$ & \\
\hline \multicolumn{5}{|l|}{ Education } \\
\hline Illiterate & $4.192 \pm 0.625$ & \multirow{4}{*}{0.292} & $2.815 \pm 0.434$ & \multirow{4}{*}{0.803} \\
\hline $\begin{array}{l}\text { Under } \\
\text { Diploma }\end{array}$ & $4.369 \pm 0.476$ & & \pm 0.246 & \\
\hline Diploma & $2.204 \pm 0.619$ & & $2.879 \pm 0.326$ & \\
\hline University & $4.225 \pm 0.848$ & & $2.714 \pm 0.393$ & \\
\hline
\end{tabular}

Table 1. Frequency of Hope and Spiritual Well-Being Score based on Demographic Characteristic

\begin{tabular}{|c|c|c|c|}
\hline Score & Score Range & $\begin{array}{c}\text { Earn Score } \\
\text { Range }\end{array}$ & Mean \pm SD \\
\hline \begin{tabular}{|c|}
$\begin{array}{c}\text { Spiritual well- } \\
\text { being }\end{array}$ \\
\end{tabular} & $20-120$ & $37-108$ & $4.22 \pm 0.61$ \\
\hline $\begin{array}{l}\text { Religious well- } \\
\text { being }\end{array}$ & $10-60$ & $21-55$ & $4.48 \pm 0.65$ \\
\hline $\begin{array}{l}\text { Existential well- } \\
\text { being }\end{array}$ & $10-60$ & $16-53$ & $3.92 \pm 0.68$ \\
\hline Hope & $12-48$ & $23-42$ & $2.84 \pm 0.38$ \\
\hline
\end{tabular}

\begin{tabular}{|c|c|c|c|c|}
\hline Variables & $\begin{array}{c}\text { Spiritual } \\
\text { Well-Being } \\
\text { Score } \\
\end{array}$ & $\mathbf{P}$ & Hope Score & $\mathbf{P}$ \\
\hline \multicolumn{5}{|l|}{ Cancer type } \\
\hline Digestion & $4.235 \pm 0.422$ & & $2.777 \pm 0.435$ & \multirow{4}{*}{0.658} \\
\hline Blood & $4.278 \pm 0.555$ & & $2.895 \pm 0.398$ & \\
\hline Breast & $4.055 \pm 0.604$ & & \begin{tabular}{|l|}
$2.861 \pm 0.277$ \\
\end{tabular} & \\
\hline Other & $4.220 \pm 0.614$ & & $2.798 \pm 0.384$ & \\
\hline $\begin{array}{c}\text { Period of } \\
\text { Chemotherapy }\end{array}$ & & & & \\
\hline 2 & $4.181 \pm 0.515$ & \multirow{3}{*}{0.800} & $2.758 \pm 0.373$ & \multirow{3}{*}{0.292} \\
\hline $3-6$ & $4.191 \pm 0.655$ & & $2.919 \pm 0.347$ & \\
\hline$>6$ & $4.271 \pm 0.654$ & & $2.850 \pm 0.424$ & \\
\hline $\begin{array}{c}\text { Treatment } \\
\text { except } \\
\text { chemotherapy }\end{array}$ & & & & \\
\hline Traditional & $4.450 \pm 0.212$ & \multirow{5}{*}{0.575} & $3.083 \pm 0.000$ & \multirow{5}{*}{0.86} \\
\hline Surgery & $4.196 \pm 0.579$ & & \begin{tabular}{|l|}
$2.830 \pm 0.361$ \\
\end{tabular} & \\
\hline Radiotherapy & $3.950 \pm 0.804$ & & $2.904 \pm 0.371$ & \\
\hline $\begin{array}{l}\text { Surgery and } \\
\text { radiotherapy }\end{array}$ & $4.562 \pm 0.816$ & & $2.729 \pm 0.524$ & \\
\hline None & $4.234 \pm 0.604$ & & \begin{tabular}{|l|}
$2.841 \pm 0.389$ \\
\end{tabular} & \\
\hline
\end{tabular}

Table 3. Frequency of Hope and Spiritual Well-Being Score based on Clinical Characteristic

\section{DISCUSSION}

Results of this study showed that the spiritual well-being scores of most patients undergoing chemotherapy (90.6\%) were at an average level, which is consistent with previous. ${ }^{22,24}$ Only about $1 \%$ of patients had low spiritual well-being, which is in contrast with the study who reported the spiritual well-being of cancer patients as low. ${ }^{27}$ A possible cause of this difference may be due to the type and stage of the disease, duration of diagnosis, support and quality of care. The score of religious well-being of the studied units were higher than their existential well-being which could be due to cultural, religious and social conditions of the country because people pay attention to the religious issues to adapt to critical circumstances and it is in line with previous conducted study in Iran. ${ }^{28}$ Spirituality plays a significant role in coping with the stress of chronic illness in old age. ${ }^{29}$ Also, it 
has shown that higher levels of spiritual well-being is associated with the reduction of psychological distress such as depression and despair. ${ }^{30}$ Nurses should take the necessary measures to promote the spiritual well-being of patients undergoing chemotherapy. The average of spiritual well-being was more in men than in women which is in line with other study, 31 but is in contrast with the results of other study. ${ }^{17}$ Although, one-way ANOVA showed that education was influential on spiritual well-being, but the level of spiritual well-being and hope in people with less than a diploma was more than other degrees, but the results of study conducted by Nelson ${ }^{23}$ did not show a significant correlation between educational level and spiritual wellbeing. In the circumstances that people are involved with severe illnesses or impending death, their spiritual dimensions are very impressed by the level of education. 32 It is possible that specific culture of an area, difference in level of education, more active social role of men, especially in religious and cultural centres play a role in this regard.

The results showed that the time of disease diagnosis is inversely related to the level of hope and spiritual well-being, i.e. the faster the diagnosis of disease had happened, the better hope for healing and continuing life and higher levels of spirituality. Although, no similar trend was found in similar literature, but it seems to be a natural trend. When faster diagnosis happens, there would be less pain and other consequences and the outcome would be more useful. According to Table No. 1, there was not a significant relationship among groups in terms of spiritual well-being with regard to cases such as age, marital status, location, type of cancer and measures other than chemotherapy ( $p>0.05$ ) and it is consistent with the results of other study in Iran. ${ }^{27}$ Considering the point that God is willing to solve my problems and I have a special goal to stay alive, it clarifies the issue that spiritual well-being is an important dimension of life which makes life goal-oriented and meaningful. Spirituality and its experience can be beneficial in creating adaptability. Cancer patients who have a high spiritual wellbeing can even pass their final parts of disease properly. ${ }^{33}$ Recent studies have also indicated that there is a strong connection between spirituality, religion and mental performance of patients with different aspects or impending death. $24,27,30$ There was a significant relationship between hope and spiritual well-being in patients undergoing chemotherapy, which is consistent with the results of other studies. $^{24,34}$ In this regard having a connection with a higher spiritual power gives the human the assurance that a stronger power is always supporting them. These persons can pass the difficult conditions easier and suffer from lower stress and tensions and as a result they are optimistic and are more hopeful for future. 35 Moreover, the importance and positive role of spiritual beliefs, they stated that the patients who recover sooner and have higher spiritual well-being have stronger religious beliefs and they use positive confronting methods in their daily life such as forgiveness, seeking for spiritual relationship with God, friendship with religious people, getting spiritual and social support, being hopeful and knowing God as a benefactor and merciful. ${ }^{36}$ However, the results of this study was not consistent with the study of Vellone et al, who did not report a significant relationship between hope and spiritual well-being, whereas they reported a significant relationship between hope and family support, relationship with friends and presenting medical data by the physicians and nurses. ${ }^{37}$ It is likely that this condition indicated the point that spirituality and religion are not used equally in different societies and individuals, cultural and social values are effective and nurses should pay proper attention to these issues. There was not a significant relationship between hope and spiritual wellbeing and demographic information of patients. Considering the fact that the role of nurses and doctors in treating incurable disease are more and more taken into consideration and since religious beliefs are personal issues; therefore, the patients expect the doctors and health care staff respect their religious beliefs. On the other hand, cancer patients who are coping with their disease by relying on spiritual matters should be able to count on the help and support of the health authorities in this field. Such support can be provided through information to patients about individuals or groups that can influence them in this regard. Doctors and health care officials attempt to satisfy the patients' need, but they may not participate in their religious activities and make no interference. In this way, measures including choosing methods of treatment and caring while considering the religious and spiritual perspectives of the patient, encouraging relying on religious and spiritual beliefs in confronting disease, encouraging the patients to consult with their religious leaders, referring the patients to the clergies or the supportive group of the hospital who can be effective with regard to spiritual issues during the process of treatment, referring the patient for treatments which promote mental health could be helpful in promotion of spiritual well-being and hope and reaching to the effective consequence of keeping and promoting the level of hope in the life of these patients. Considering the aforementioned issues and the fact that no study had been conducted in Iran on the correlation between hope and spiritual well-being, it is recommended to conduct more researches in clarifying hope in chronic patients and the effective factors leading to hope by emphasising the cultural and religious issues, especially for passing the difficult stages of diseases and accepting overwhelming treatments.

Therefore, it could be mentioned that spiritual well-being is effective on the quality of disease and recovery and patient's viewpoint to the disease and its process. It seems that health care team, specifically nurses, should pay a significant attention to spiritual well-being and make it a priority along with other dimensions of care. ${ }^{38}$ In a study conducted, research on the advanced cancer patients claimed that spiritual well-being decreased hopelessness and despair in them. ${ }^{39}$

In this study the mean scores of hope in patients undergoing chemotherapy was $2.841 \pm 0.389$, which was above average level. In other words $67.4 \%$ had mediocre level of hope and $28.4 \%$ had high level of hope, which was consistent with the results of other studies. ${ }^{40,41}$ In this study, the average score of hope were in the range of 35 - 40 out of 48. However, this is not compatible with the results of Dehbashi et al, which showed low level of hope in haemodialysis patients in Zahedan city. ${ }^{42}$ The reason for this difference can be different factors such as cultural and religious differences of the studied societies, using financial, therapeutic, caring and supportive facilities and individual and professional characteristics are effective on hope as well. 
Snyder and Lopez claimed that hopeful thinking about cancer made people make both more effort to resolve their problem and also show more consistency and adaptability. 43 Also, in a qualitative study entitled the experience of patients undergoing chemotherapy and claimed that patients considered undergoing chemotherapy as a new birth and were hopeful of its results as a new horizon in life. 44 Creating hope by nurses is very important, because hope is the factor of continuity of life expectancy in cancer patients, which also assists the compatibility of families and individuals in difficult circumstances. ${ }^{11}$

Although in this study as the age increased, especially in people over 60, hope scores lowered. There was no significant relationship between them. As much as age increased in the elderly, the hope for treatment decreased. Cancer diagnosis in elderly makes more complications and ambiguities in comparison with younger ones. 45 Moreover, hope is inversely related to the time of diagnosis. Some of the main reasons for this are likely to be the pain and problems in the process of disease.

Non-random sampling and the population of the patients receiving chemotherapy referring to only one centre should be considered in generalisability of the results. Questions about spiritual well-being can be personal and people may not be very willing to offer their opinions, so it was tried to assure the confidentiality of data and attract the patient's trust. It is recommended to study and compare different strategies of promoting hope and spiritual well-being in the patients. Depth review using qualitative methods to determine the criteria for the spiritual well-being and hope in patients is recommended as well.

\section{CONCLUSION}

Considering the relationship between spiritual health and hope, identifying the spiritual needs of patients undergoing chemotherapy is necessary. Nurses can provide favourable conditions by playing supportive and counselling roles in promoting hope and spiritual well-being. In order to reduce the frustration and anxiety and increase the level of optimism, accurate and timely diagnosis and treatment and attention to older and female patients is recommended.

\section{ACKNOWLEDGEMENTS}

Authors would like to express special thanks of gratitude for supporting and providing found by research council of Kurdistan University of Medical Sciences as well as we thank the managers of hospitals and dear patients who participated in this study.

\section{Funding/Support}

The present study is the result of research project that has been approved by the research council of Kurdistan University of Medical Sciences, Sanandaj, Iran, No. IR.REC.MUK.1394.149.

\section{REFERENCES}

[1] WHO. Cancer health topic. 23 Nov, 2013. http://www.who.int/cancer/en/index.html.2013.

[2] WHO global report. Non-communicable disease country $\quad$ profiles. 2011. www.who.int/entity/nmh/publication/ncd_profile20 11/en/-29k.
[3] AMERICAN CS. Cancer facts and figures. 2013. Accessed $23 \quad$ Nov, 2013. http://www.cancer.org/acs/groups/content/@epide miologysurveilance/documents/document/acspc036845.pdf.

[4] Kolahdoozan S, Sadjadi A, Radmard AR, et al. Five common cancers in Iran. Archives of Iranian Medicine 2010;13(2):143-6.

[5] Ignoffo R, Rosenbaum E. What happens in chemotherapy? Everyone's Guide to cancer therapy. Revised $5^{\text {th }}$ edn. Kansas City, MS: Andrew McMeel Publishing 2008.

[6] Roffe L, Schmidt K, Ernst E. A systematic review of guided imagery as an adjuvant cancer therapy. Psycho-Oncology 2005;14(8):607-17.

[7] Baker PD, Ellett ML. Measuring nausea and vomiting in adolescents: a feasibility study. Gastroenterology Nursing 2007;30(1):18-28.

[8] Takahashi T, Hondo M, Nishimura K, et al. Evaluation of quality of life and psychological response in cancer patients treated with radiotherapy. Radiation Medicine 2008;26(7):396-401.

[9] Chi GC. The role of hope in patients with cancer. Oncology Nursing Forum 2007;34(2):415-24.

[10] Duggleby W, Holtslander L, Kylma J, et al. Metasynthesis of the hope experience of family caregivers of persons with chronic illness. Qualitative Health Research 2010;20(2):148-58.

[11] Kylmä J, Duggleby W, Cooper D, et al. Hope in palliative care: an integrative review. Palliative and Supportive Care 2009;7(3):365-77.

[12] McClement SE, Chochinov HM. Hope in advanced cancer patients. European Journal of Cancer 2008;44(8):1169-74.

[13] Rustøen T, Wahl AK, Hanestad BR, et al. Hope in the general Norwegian population, measured using the Herth Hope Index. Palliative \& Supportive Care 2003;1(4):309-18.

[14] Mattioli JL, Repinski R, Chappy SL. The meaning of hope and social support in patients receiving chemotherapy. Oncology Nursing Forum 2008;35(5):822-9.

[15] Arslan S, Celebioglu A, Tezel A. Depression and hopelessness in Turkish patients with cancer undergoing chemotherapy. Japan Journal of Nursing Science 2009;6(2):105-10.

[16] Chuengsatiansup K. Spirituality and health: an initial proposal to incorporate spiritual health in health impact assessment. Environmental Impact Assessment Review 2003;23(1):3-15.

[17] Allahbakhshian M, Jaffarpour M, Parvizy S, et al. A Survey on relationship between spiritual wellbeing and quality of life in multiple sclerosis patients. Zahedan Journal of Research in Medical Sciences 2010;12(3):29-33.

[18] Marandi A, Azizi F. The position, based on the difficulties of defining and spiritual health of the population-Islam. J Medical Ethics 2010;4(14):11-21. [Persian].

[19] Burkhardt MA, Nagai-Jacobson MG. Spirituality: living our connectedness. New York: Delmar Thomson Learning 2002. 
[20] Ellison LL. The spiritual well-being scale. 2006.

[21] Fatemi SN, Rezaei M, Givari A, et al. Prayer and spiritual well-being in cancer patients. J Iran Institute Health Sci Res 2006;5(4):295-303. (Persian).

[22] Mohammadi SZ, Tajvidi M. Relationship between spiritual well-being with hopelessness and social skills in Beta-thalassemia major adolescents (2010). Modern Care Journal 2011;8(3):116-24.

[23] Nelson CJ, Rosenfeld B, Breitbart W, et al. Spirituality, religion and depression in the terminally ill. Psychosomatics 2002;43(3):213-20.

[24] Baljani E, Khashabi J, Amanpour E et al. Relationship between spiritual well-being, religion, and hope among patients with cancer. Hayat 2011;17(3):27-37.

[25] Peplau LA, Perlman D. Perspectives on loneliness. In: Peplau LA, Perlman D, eds. Loneliness: a sourcebook of current theory, research and therapy. New York: John Wiley \& Sons 1982: p. 1-20.

[26] Herth K. Enhancing hope in people with a first recurrence of cancer. Journal of Advanced Nursing 2000;32(6):1431-41.

[27] Moghimian M, Salmani F. The study of correlation between spiritual well-being and hope in cancer patients referring to Seyyedo Shohada TrainingTherapy Center of Isfahan University of Medical Sciences, 2010, Isfahan, Iran. Qom University of Medical Sciences Journal 2012;6(3):40-5.

[28] Aghahoseini S, Rahmani A, Abdollahzadeh F, et al. Spiritual health in cancer patients and its related factors. Ghom Journal of Research In Medical Sciences 2009;5(3):7-12. (Persian).

[29] Livneh H, Lott S, Antonak R. Patterns of psychosocial adaptation to chronic illness and disability: a cluster analytic approach. Psychology, Health \& Medicine 2004;9(4):411-30.

[30] Rowold J. Effects of spiritual well-being on subsequent happiness, psychological well-being and stress. Journal of Religion and Health 2011;50(4):950-63.

[31] Büssing A, Ostermann T, Matthiessen PF. Adaptive coping and spirituality as a resource in cancer patients. Breast Care 2007;2:195-202.

[32] Leung KK, Chiu TY, Chen CY. The influence of awareness of terminal condition on spiritual wellbeing in terminal cancer patients. Journal of Pain and Symptom Management 2006;31(5):449-56.

[33] Lin HR. Searching for meaning: narratives and analysis of US-resident Chinese immigrants with metastatic cancer. Cancer Nursing 2008;31(3):250-8.
[34] Hong IW, Ow R. Hope among terminally ill patients in Singapore: an exploratory study. Soc Work Health Care 2007;45(3):85-106.

[35] Seligman ME, Csikszentmihalyi M. Positive psychology: an introduction. New York, NY: Springer Netherlands 2014: p. 279-98.

[36] Ai AL, Park CL, Huang B, et al. Psychosocial mediation of religious coping styles: a study of short-term psychological distress following cardiac surgery. Personality and Social Psychology Bulletin 2007;33(6):867-82.

[37] Vellone E, Rega ML, Galletti C, et al. Hope and related variables in Italian cancer patients. Cancer Nursing 2006;29(5):356-66.

[38] Newlin K, Knafl K, Melkus GD. African-American spirituality: a concept analysis. Advances in Nursing Science 2002;25(2):57-70.

[39] McClain CS, Rosenfeld B, Breitbart W. Effect of spiritual well-being on end-of-life despair in terminally-ill cancer patients. The Lancet 2003;361(9369):1603-7.

[40] Alberto J, Joyner B. Hope, optimism and self-care among Better Breathers Support Group members with chronic obstructive pulmonary disease. Applied Nursing Research 2008;21(4):212-7.

[41] Orlandi FdS, Pepino BG, Pavarini SCI, et al. The evaluation of the level of hope of elderly chronic kidney disease patients undergoing hemodialysis. Revista da Escola de Enfermagem da USP 2012;46(4):900-5.

[42] Dehbashi F, Sabzevari S, Tirgari B. The relationship between spiritual well-being and hope in hemodialysis patients referring to the Khatam Anbiya hospital in Zahedan 2013-2014. Medical Ethics Journal 2015;8(30):77-96.

[43] Snyder CR, Lopez SJ. Oxford handbook of positive psychology. $2^{\text {nd }}$ edn. New York, USA: Oxford University Press 2009.

[44] Nasrabadi AN, Mohammadpour A, Fathi M. New horizon in life: experiences of patients receiving chemotherapy. Global Journal of Health Science 2016;8(4):102-8.

[45] Duggleby W, Ghosh S, Cooper D, et al. Hope in newly diagnosed cancer patients. Journal of Pain and Symptom Management 2013;46(5):661-70. 